\title{
Research on Thermal Conductivity of Grouting Material for Underground Heat Exchanger of GSHP System
}

\author{
Lele $\mathrm{Yu}$ \\ Department of Civil Engineering \\ Zhejiang University of Technology \\ Hangzhou, China \\ javier2625@163.com
}

\author{
Wanlu Huang \\ Department of Civil Engineering \\ Zhejiang University of Technology \\ Hangzhou, China \\ amlia1206@163.com
}

\begin{abstract}
As we know, thermal properties of grouting material between the pipe and the stratum is one of the most factor to the efficiency and cost of the ground-source heat pump system. In this paper, based on the research of the grouting material at home and abroad, it was tested with a different ratios of bentonite-sand by steady-state gauges( JTRG-III conductometers with steady state thermal flow). The thesis involves physical characteristic indexs of the testing, such as the density of the bentonite-sand, moisture content, void ratio, saturation and coefficient of thermal conductivity etc, and it will be adjusted to provide reliable basis for the ground-source heat pump technology application.
\end{abstract}

Keywords-coefficient of thermal conductivity; groundsource heat pump; ground-buried pipe heat exchanger; the grouting material; experiment

\section{INTRODUCTION}

Today, energy is a remarkable problem. With the development of economy, science and technology and the improvement of people's living standards, the traditional pattern of heating, cooling will be affected to various degree. Geothermal energy, as a new renewable energy, is clean, pollution-free and huge stockpile, having broad application prospects. The system of ground-source heat pump uses the geothermal resources which stored in the shallow crust for heating and air-conditioning for buildings, because of the deeper strata keeps the temperatures constant throught the seasons in undisturbed conditions, which is much higher than the outdoor temperature in winter but lower than the outdoor temperature in summer, the ground source heat pump can overcome the technical barriers of air source heat pump and it can heighten the efficiency of the heat pump greatly. In addition, getting heat from the underground in winter for heating for buildings, at the same time, making the earth temperature decrease, storing the cold energy, which can used in summer; and giving out heat to the underground in summer, storing the heat, which can used in winter. So the earth have played an important role in energy storage in the system of ground-source heat pump, which is further increased the efficiency of energy use of air conditioning system throughout the year. This not only makes the heating efficiency in winter improved, also makes the power consumption of air conditioning in summer reduced greatly. So the technology of ground-source heat pump has a good energy-saving and environmental benefits. It is called a technology in the 21st century for the characteristics of energy-saving and environmental protection.

The underground heat exchanger is the key of the technology of the system of ground-source heat pump, the intensity of the heat exchange ability of the underground heat exchanger affect the efficiency of the system of ground-source heat pump directly,and the degree of thermal conductivity of grouting material determines the effect of heat exchanger. The effective grouting material can prevent the influence about the effect of heat transfer of buried tube heat exchanger caused by freezing,shrinking and crusting of soil, can enhance the effect of heat transfer of the outlet of buried tube heat exchanger, at the same time it also can prevent the adverse effects of underground pollutants on the buried tube, so having an important influence on the performance of ground-source heat pump by selecting the appropriate grouting material. The grouting material with good physical properties can enhance the process of themal conductivity between pipeline and stratum, and then reducing the designed dimensions of the underground heat exchanger and initial investment cost.

This article will be determined the impact of the density, moisture content and other properties of grouting material on its thermal capacity by the experiment, establishing the relationship about the effect on the performance of mixture of thermal conductivity by the various substances of mixtures, finding the best grouting materials, improving the capacity of heat transfer of the underground heat exchanger, and reducing the length of buried tube, the cost of installation of the system and the actual running costs.

\section{TEST METHODOLOGY}

The grouting material belongs to the porous medium, and it's basic parameters of the thermal properties incloud density $[\mathrm{kg} / \mathrm{m} 3]$, the moisture content [\%] and thermal conductivity $\mathrm{K}[\mathrm{W} / \mathrm{m} \cdot \mathrm{K}]$, etc. All parameters can be measured by different experiments. 


\section{A. The test of density}

Generally, the density of soil is measured with"Ring Sampler Method". Using a circular knife (down-blade) on a flattened surface of the sample of the undisturbed soil, and slashing soil out of the ring slowly, then slashing, at the same time pressing, making the soil with the natural state full filled in the ring, in the end, weighing the mass of soil which in the ring, and calculating the ratio of the mass and the ring's volume. It is density.

The formula of density:

$$
\rho=\frac{m_{0}}{V}\left[\mathrm{~kg} / \mathrm{m}^{3}\right]
$$

In the formula:

$$
\begin{aligned}
& \rho \_ \text {The density of grouting material }[\mathrm{kg} / \mathrm{m} 3] ; \\
& m_{0} \_ \text {The mass of grouting material }[\mathrm{kg}] ; \\
& V — \text { The volume of grouting material }[\mathrm{m} 3]
\end{aligned}
$$

\section{B. The test of moisture content}

Generally, the moisture of soil is measured with "Drying Method". First, weighing the wet mass of a small, original state soil, and placing in the oven with $100 \sim 150^{\circ} \mathrm{C}$ until the weight unchanged, then weighing the dry mass, the moisture content of soil is the ratio of the difference of mass between the wet and dry soil and the dry mass of soil.

The formula of moisture content:

$$
\omega=\frac{m-m_{s}}{m_{s}} \times 100 \%
$$

In the formula:

$\omega-$ Moisture content of grouting material [\%];

$m$ - The mass of grouting material at the time of sampling [kg];

$$
m_{s} \text { —Absolutely dry mass of grouting material }[\mathrm{kg}]
$$

\section{The test of thermal conductivity}

The coefficient of thermal conductivity is an essential parameters of the thermal properties of matter, and it has a wide range of changes in values with different kinds of material. Generally, the coefficient of thermal conductivity of metal is the biggest, and the coefficient of thermal conductivity of non-metallic solid material is $0.025 \sim 3.0[\mathrm{~W} / \mathrm{m} \cdot \mathrm{K}]$ in general. The coefficient of thermal conductivity can be affected by temperature, humidity and density, the coefficient of thermal conductivity increases with raising of temperature and humidity, because motionless air is a good thermal insulation material(The coefficient of thermal conductivity is less than $0.25[\mathrm{~W} / \mathrm{m} \cdot \mathrm{K}]$ ), the coefficient of thermal conductivity decreases with raising of the porpsity of material. The coefficient of thermal conductivity of liquid is $0.01 \sim 0.7[\mathrm{~W} / \mathrm{m} \cdot \mathrm{K}]$, and the coefficient of thermal conductivity decreases with raising of the temperature. And the coefficient of thermal conductivity of gas is small in the range of $0.006 \sim 0.5[\mathrm{~W} / \mathrm{m} \cdot \mathrm{K}]$, the coefficient of thermal conductivity increases with raising of the temperature.

The formula of coefficient of thermal conductivity:

$$
K=-\frac{q}{\partial t / \partial n}
$$

In the formula:

$q$ - Thermal flux of the normal direction [W/m2];

$\partial t / \partial n$-Temperature gradient of the normal

direction $[\mathrm{K} / \mathrm{m}]$

The coefficient of thermal conductivity is a major factor which is the most critical and determining the level of efficiency of the system in describing the nature of grouting material.Previous studies indicate that its coefficient of thermal conductivity has function relationship to temperature, density, void ratio, saturation and moisture content,expressing as $K=f\left(t, \rho, w, e, S_{v}\right)$.

The factors in the above,saturation and void ratio is also determined when the material composition of grouting material is determined, and the effect on the coefficient of thermal conductivity has not been too great in the constant temperature.So,the density and moisture play a decisive role on the coefficient of thermal conductivity,expressing as $K=f(\rho, w)$.

Researching the difference of coefficient of thermal conductivity by a different mixing proportion for finding more economical and efficient grouting material. Testing by steady type measuring instrument(JTRG-III conductometers with steady state thermal flow). Using the steady type measuring instrument for measuring have a certain influence on the accuracy of experimental results. The steady type measuring instrument required the test piece is solid model in the course of the experiment, which is difference with the actual grouting material. So we adding the same silt into experimental material of each group, increasing the cohesion and the power of consolidation of samples, increasing its consistency, making the style of block meet the requirements of instruments.

This experiment make five samples in total, respectively, a sample of $300 \mathrm{~mm} \times 300 \mathrm{~mm} \times 30 \mathrm{~mm}$ and four little samples of $100 \mathrm{~mm} \times 100 \mathrm{~mm} \times 30 \mathrm{~mm}$. Composition of each experimental sample is shown in Table 1 , the coefficient of thermal conductivity read once about every ten minutes, each group take the average by measuring three coefficient of thermal conductivity. The sand is medium, containing a small amount of round gravel; excluding the moisture content of silt and sand. The measured coefficient of thermal conductivity are shown in Table 1. 
TABLE I. COMPOSITION AND COEFFICIENT OF THERMAL CONDUCTIVITY OF EACH GROUP

\begin{tabular}{|c|c|c|c|c|c|c|c|}
\hline & $\begin{array}{c}\text { Sand } \\
\text { (g) }\end{array}$ & $\begin{array}{l}\text { Bento } \\
\text { nite } \\
\text { (g) }\end{array}$ & $\underset{\text { Wate }}{\mathbf{r}}$ & \multicolumn{3}{|c|}{$\begin{array}{l}\text { Coefficient of thermal } \\
\text { conductivity } k(W / m \cdot K)\end{array}$} & \multirow{2}{*}{$\begin{array}{c}\begin{array}{c}\text { The } \\
\text { avera } \\
\text { ge } \\
(\mathbf{W} / \mathbf{m} \\
\cdot \mathbf{K})\end{array} \\
\begin{array}{l}0.390 \\
5\end{array}\end{array}$} \\
\hline 1 & $2200 \mathrm{~g}$ & $600 \mathrm{~g}$ & $\begin{array}{l}1800 \\
\mathrm{ml}\end{array}$ & $\begin{array}{l}0.392 \\
4\end{array}$ & $\begin{array}{l}0.393 \\
9\end{array}$ & $\begin{array}{l}0.385 \\
2\end{array}$ & \\
\hline 2 & $350 \mathrm{~g}$ & $100 \mathrm{~g}$ & $100 \mathrm{ml}$ & $\begin{array}{l}1.477 \\
6\end{array}$ & $\begin{array}{l}1.465 \\
0\end{array}$ & $\begin{array}{l}1.473 \\
3\end{array}$ & $\begin{array}{l}1.472 \\
0\end{array}$ \\
\hline 3 & $300 \mathrm{~g}$ & $150 \mathrm{~g}$ & $100 \mathrm{ml}$ & $\begin{array}{l}0.996 \\
1\end{array}$ & $\begin{array}{l}0.982 \\
9\end{array}$ & $\begin{array}{l}0.990 \\
1\end{array}$ & $\begin{array}{l}0.989 \\
7\end{array}$ \\
\hline 4 & $275 g$ & $125 \mathrm{~g}$ & $100 \mathrm{ml}$ & 1.369 & $\begin{array}{l}1.357 \\
6\end{array}$ & $\begin{array}{l}1.358 \\
7\end{array}$ & $\begin{array}{l}1.361 \\
8\end{array}$ \\
\hline 5 & $250 \mathrm{~g}$ & $150 \mathrm{~g}$ & $100 \mathrm{ml}$ & $\begin{array}{l}1.282 \\
3\end{array}$ & $\begin{array}{l}1.279 \\
9\end{array}$ & $\begin{array}{l}1.279 \\
8\end{array}$ & $\begin{array}{l}1.280 \\
7\end{array}$ \\
\hline & $\begin{array}{c}\text { Silt } \\
\text { (g) }\end{array}$ & $\begin{array}{c}\text { Total } \\
\text { mass } \\
(\mathrm{g})\end{array}$ & $\begin{array}{c}\text { Conte } \\
\text { nt of } \\
\text { bento } \\
\text { nite }\end{array}$ & $\begin{array}{c}\text { Conte } \\
\text { nt of } \\
\text { sand }\end{array}$ & $\begin{array}{c}\text { Conte } \\
\text { nt of } \\
\text { water }\end{array}$ & $\begin{array}{l}\text { Volu } \\
\text { me } \\
(\mathrm{cm} 3)\end{array}$ & $\begin{array}{c}\text { Densi } \\
\text { ty } \\
\text { (g/ } \\
\text { cm3) }\end{array}$ \\
\hline 1 & 0 & $450 \mathrm{~g}$ & $\begin{array}{l}13.33 \\
\%\end{array}$ & $\begin{array}{l}48.89 \\
\%\end{array}$ & $\begin{array}{l}40.00 \\
\%\end{array}$ & 2700 & 1.67 \\
\hline 2 & $50 \mathrm{~g}$ & $550 \mathrm{~g}$ & $\begin{array}{l}18.18 \\
\%\end{array}$ & $\begin{array}{l}63.64 \\
\%\end{array}$ & $\begin{array}{l}18.18 \\
\%\end{array}$ & 300 & 1.83 \\
\hline 3 & $50 \mathrm{~g}$ & $540 \mathrm{~g}$ & $\begin{array}{l}27.78 \\
\%\end{array}$ & $\begin{array}{l}55.56 \\
\%\end{array}$ & $\begin{array}{l}18.52 \\
\%\end{array}$ & 300 & 1.8 \\
\hline 4 & $50 \mathrm{~g}$ & $490 \mathrm{~g}$ & $\begin{array}{l}25.51 \\
\%\end{array}$ & $\begin{array}{l}56.12 \\
\%\end{array}$ & $\begin{array}{l}20.41 \\
\%\end{array}$ & 300 & 1.63 \\
\hline 5 & $50 \mathrm{~g}$ & $500 \mathrm{~g}$ & $\begin{array}{l}30.00 \\
\%\end{array}$ & $\begin{array}{l}50.00 \\
\%\end{array}$ & $\begin{array}{l}20.00 \\
\%\end{array}$ & 300 & 1.67 \\
\hline
\end{tabular}

Based on past experimental experience, the thrid group of data can be found different, so using three groups of data(the third, fourth and fifth group) for researching in the following relation curve.

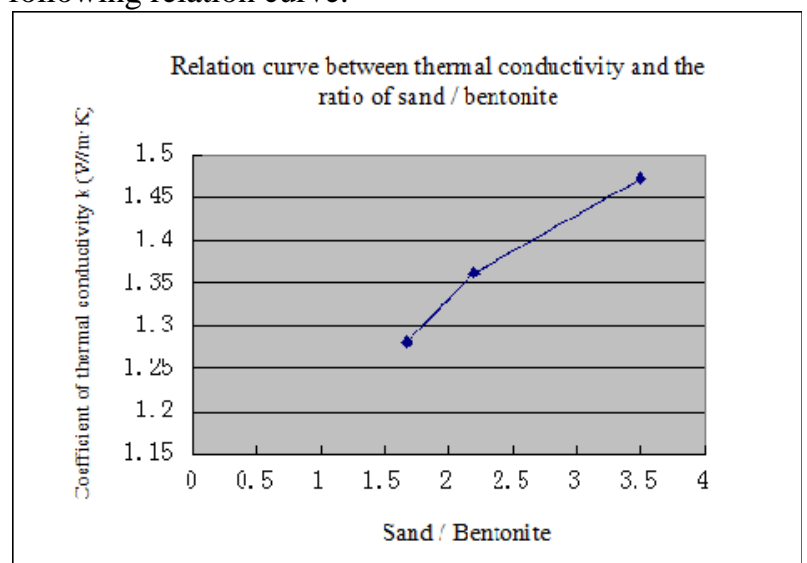

Figure 1. Relation curve between thermal conductivity and the ratio of sand / bentonite

From Fig.1, coefficient of thermal conductivity increases with raising of the ratio of sand / bentonite; coefficient of thermal conductivity increases faster when the proportional coefficient is small; as the ratio of sand / bentonite increases, the increasing trend is smaller. From the literature, coefficient of thermal conductivity is $0.7-0.9$, it is higher in this paper, because of the increase of the content of sand in a preliminary analysis.And becasuse adding the silt, the sample didn't appear crack. Therefore, this paper's ratio meets the actual circs better, but still need to be tested by engineering practice.

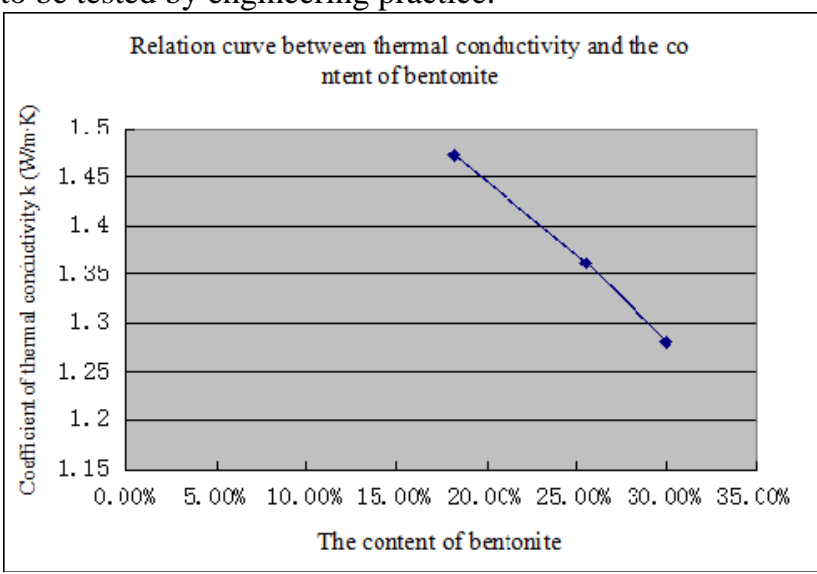

Figure 2. Relation curve between thermal conductivity and the content of bentonite

From Fig.2, coefficient of thermal conductivity decreases with raising of the content of bentonite, and the tendency of decreasing is diminishing. Combined with figure 3 , while the content of bentonite increased, the content of sand decreased reciprocally, leading to coefficient of thermal conductivity decreasing.

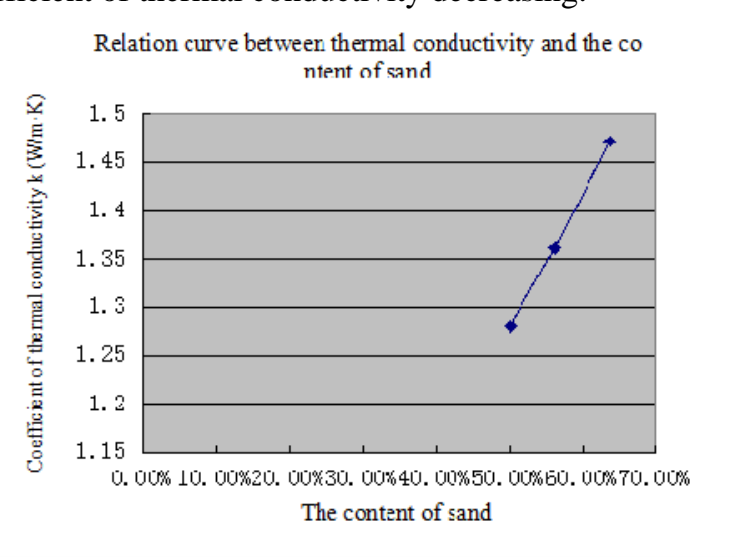

Figure 3. Relation curve between thermal conductivity and the content of sand

From Fig.3, coefficient of thermal conductivity increases with raising of the content of sand, its scales linearly on the whole.

\section{CONCLUSIONS}

From the result of density, moisture content and the different ratio of coefficient of thermal conductivity of the grouting material, in this paper, coefficient of thermal conductivity increases with raising of the content of sand, its scales linearly on the whole; coefficient of thermal conductivity is inversely proportional to the content of bentonite, the tendency of decreasing is diminishing with raising of the content of bentonite; coefficient of thermal conductivity increases with raising of the ratio of sand / bentonite; coefficient of thermal conductivity increases faster when the proportional coefficient is small; as the ratio of sand / bentonite increases, the increasing trend is smaller. As for the optimization of grouting material, we need unifie through the theory and the practice analysis 
carries on the research, finding economic, efficient grouting materials eventually, improving the capacity of heat transfer of the underground heat exchanger.

\section{ACKNOWLEDGMENT}

The research work was supported by Natural Science Foundation of Zhejiang Province (Y14E080049) and Postdoctoral Preferred Funding of Zhejiang Province (BSH13020).

\section{REFERENCES.}

[1] Yingchun Zhuang, Kanghe Xie and Youhong Sun, "Experimental study on thermal conductivity of mixed materials of sand and bentonite,” Rock and Soil Mechanics, vol.26, Feb. 2005, pp. 261264

[2] Xinguo Li, Hongjun Wang and Jun Zhao, Lixin Li,Qiang Zhu and Qiang Lv, "Experimental study on the heat exchange performance of u-vertical underground heat exchanger by different back filler materials,” Acta Energiae Solaris Sinica, vol. 24, Dec. 2003, pp. 810-813

[3] Xiangyan Wang, Weibin Ma, Yuanfeng Huang, Yulie Gong and Yongwang Lian, "Experimental study on super absorbent polymer mixed with the original soil as backfilled material in ground source heat pump system” Rock and Soil Mechanics, vol.28, Jan. 2007, pp.23-27

[4] Zhang Q, Murphy W E. "Measurement of Thermal Conductivity for Three Borehole Fill Materials Used for GSHP [J].”ASHRAE Transaction, 2000, 106(2), pp. 434-441

[5] Yongfu Xu, Dean Sun and Ping Dong, "Swelling tests on bentonite and sand-bentonite mixture[J]," Chinese Journal of Rock Mechanics and Engineering, 2003, 22(3), pp.451-455

[6] Zhijian Wang, Quansheng Liu, "Experimental study of swelling characteristics of compacted sand-bentonite mixture[J],” Rock and Soil mechanics, 2000, 21(4), pp.331-334

[7] Heyi zeng, Zhaohong Fang, "A fluid temperature mode for vertical U-Tube geothermal heat exchangers[J],” J of ShanDong Institute of Arch. And Eng. 2002, 17(1), pp. 7-11

[8] Xinxi Zou, "Super water absorbent[M]," Chemistry Industry Publishing Company, 1991

[9] Yingchun Zhuang, Youhong Sun, Kanghe Xie, "Study on performance of backfilled soil for vertical-buried closed-loop gshp[J],” Acta Energiae Solaris Sinica, 2004, 25(4), pp.216-220

[10] Dean Shen, "Experimental study on heat transfer performance of ground source heat pump buried tube heat exchanger,"Railway Engineering, 